\title{
ВИДЫ ПРАВОВЫХ ПРЕЗУМПЦИЙ И ИХ КЛАССИФИКАЦИЯ
}

\section{TYPES OF LEGAL PRESUMPTIONS AND THEIR CLASSIFICATION}

D. Dudko

Summary. This article considers for the first time the complex qualification of legal presumptions. The significance of considering the classifications of legal presumptions is also due to the methodological significance of the research, which allows us to identify common features and patterns, and also helps to clarify the essence of the legal nature of legal presumption and their types.

Keywords: classification, legal presumptions, public administration, types, categories.

\author{
Дудко Дмитрий Анатольевич \\ Государственный советник Российской Федерации \\ 3 класса, начальник Управления урегулирования \\ налоговых споров, ПАО «ЛУКОЙЛ», Москва \\ Dmitriy.Dudko@lukoil.com
}

Аннотация. В данной статье впервые рассматривается комплексная квалификация правовых презумпций. Значимость рассмотрения классификаций правовых презумпций обусловлена также методологическим значением, проводимого исследования, которое позволяет выявить общие черты и закономерности, а также способствует выяснению сути правовой природы правовой презумпции и их видов.

Ключевые слова: классификация, правовые презумпции, государственное администрирование, виды, категории.

научным упущением, так как от ее разработки зависит эффективность, качество и оптимизация правового регулирования общественных отношений.

Однако ввиду того, что в юридической литературе встречается большое количество различных понятий правовой презумпции [1, с. 42], соответственно это порождает существование множества различных классификаций [2, с. 80], которые в рамках одного исследования рассмотреть не представляется возможным, в связи с чем, в данном параграфе остановимся на самых значимых и устоявшихся классификационных критериях. При этом, не смотря на достаточное многообразие всевозможных классификаций, до настоящего времени не выработана общая система видовых разновидностей правовых презумпций, где бы просматривалась рациональная взаимосвязь, обусловленная общей теорией.

1. Автором самой популярной терминологии, посвященной презумпции - профессор В.К. Бабаев выделяет следующие виды правовых презумпций по сфере действия [3, с. 113]:

а) общеправовые презумпции, которые имеют место практически во всех отраслях российского права, представляя собой конкретно установленные принципы, которые в силу правовой сущности не могут рассматриваться в качестве правового средства юридической техники. Поэтому общеправовые виды презумпций вполне рационально прировнять с общеотраслевыми классификационными критериями, поскольку они будут иметь место применительно к каждой отрасли права. Здесь речь идет о таких презумпциях, как, например, презумп- 
ция знания законов. Общеправовые презумпции имеют основополагающее значение в российской правовой системе. Зачастую в юридической литературе, такую разновидность приравнивают к принципам права.

Следует остановиться на исследовании конкретных видов правовых презумпций, выделяемых в рамках данной классификации.

Общеправовые презумпции являются основой для формулирования правовых презумпций в системе государственного администрирования, поскольку именно государственные органы при реализации конкретной функции осуществляют работу по правовому применению правовых норм, содержащихся в действующем законодательстве РФ.

Также следует отдельно выделить общеправовые презумпции, которые способны охарактеризовать определенное правовое поведение субъектов правоотношений, к ним относят: презумпцию добропорядочности граждан; презумпцию добросовестности; презумпцию невиновности; презумпцию знания закона;

б) из анализа юридической литературы возникает вопрос о необходимости отдельного обозначения общеотраслевых и отраслевых правовых презумпции.

Стоит отметить, что если искать ответ в соотношении общеправовых и отраслевых принципов права, где система отраслевых принципов не дублирует общеправовые, то представляется очевидным, что правовые презумпции нуждаются в отдельном обозначении для каждой конкретной отрасли права, это видится вполне рациональным, поскольку позволит не смешивать общественные отношения и термины, а при должной правовой регламентации правовых презумпций, к примеру, в государственном администрировании, способно поставить точку в дискуссионности терминологии, посвященной правовым презумпциям.

Важно сделать акцент на том, что все правовые отраслевые презумпции берут свое начало от конституционных принципов, которые и породили ряд соответствующих презумпций, например, речь идет о презумпции конституционности нормативных правовых актов, презумпции знания закона. В подтверждение обозначенного, представим позицию профессора Т.Д. Зражевской, которая в своих работах исходит из того, что в правовой доктрине имеют место правовые презумпции в конституционном праве, которые следует рассматривать как принципы, к таковым она относит презумпцию конституционности деятельности всех участников конституционных отношений; презумпцию конституционности нормативных правовых актов и презумпцию добросовестности участников конституционных правоотношений [4, с. 35].
Ценность данной классификации безусловна, особенно ввиду отсутствия фундаментальных исследований относительно рассматриваемого вопроса, недостаточной разработанности выделяемых категорий даже в конституционном праве.

Также важно отметить, что отраслевые презумпции, являющиеся определенного рода презумптивными предположениями, действующими только в определенной отрасли права, например презумпции в государственном администрировании, презумпции добросовестности контрагентов и др.

Обозначенные классификационные критерии вызывают множественные дискуссии в научном кругу, противники рассуждают несколько иначе - поскольку отрасли права тесно взаимосвязаны между собой, более того презумпции одной отрасли, могут быть использованы в другой (к примеру, презумпция невиновности), поэтому многие исследователи не поддерживают такую классификацию.

Как представляется, отказываться от представленной классификации не рационально, она необходима для разграничения презумпций по отраслям, поскольку они все же отличаются (к примеру, презумпция невиновности в уголовном и административном праве не равнозначные понятия) и требуют соответствующей правой регламентации в соответствии со спецификой каждой отрасли права.

Но стоит заметить, что представленная классификация, является общей и не раскрывает всего многообразия правовых презумпций, но при этом делит все презумпции на ключевые блоки, оспаривать которые мы не беремся из-за нерациональности. Поэтому считаем, что данная видовая конструкция имеет место и будет определять последующие возможные классификации;

в) межотраслевые правовые презумпции, которые основаны на однотипных закономерностях и юридических фактами, закрепленных в правовых нормах различных отраслей права. К их числу можно отнести, например, презумпции процессуальной дееспособности (правосубъектности) или истинности судебного решения.

Однако как отмечалось выше, данная классификационная составляющая может запутать правоприменителя, но в случаях использования аналогии права или закона имеет место для существования;

г) поэтому в данном случае весьма целесообразно, опираясь на выделение группы общеправовых презумпций, обозначить специально правовые (отраслевые) 
презумпции, которые будут иметь место непосредственно при реализации государственного администрирования, например:

- презумпция добросовестности налогоплательщика;

- презумпция добросовестности уполномоченного должностного лица, при оказании государственной услуги населению;

- презумпция законности приказа уполномоченного должностного лица; - презумпция интересов государственной безопасности;

- презумпция добросовестности должностных лиц и законности их действий и решений;- презумпция законности административного акта;

- презумпция действия административного акта при утрате им юридической силы;

- презумпция открытости информации в деятельности органов исполнительной власти (далее ОИВ) и их должностных лиц;

- презумпция возмещения морального вреда неправомерными действиями ОИВ и их должностными лицами; - презумпция добросовестности субъектов электронной коммуникации в сфере оказания государственных услуг через Портал государственных услуг РФ (https://www. gosuslugi.ru) и др.

Обозначенные выше базовые классификационные критерии были выделены нами сучетом их практической значимости для правоприменителя и позволяют схематизировать существующий пласт правовых презумпций для наиболее эффективной реализации превенционных положений закона при осуществлении государственного администрирования [5, с. 29].

2. Многие ученые подразделяют правовые презумпции по способу закрепления на прямые и косвенные. Где правовую презумпцию следует отнести к прямой в том случае, если она непосредственно закреплена в нормативно-правовом акте следующими способами:

1) с помощью выражений - «пока не будет доказано иное», «если кто-либо не докажет», «предполагается» и др. Например, ст. 1.5 КоАП РФ, именуется как «Презумпция невиновности», содержащая такие фразы как «пока вина не будет доказана» и «не обязано доказывать свою невиновность;

2) с использованием категории - «презумпция» в названии статьи нормативно-правового акта, раскрывающей сущность этого понятия совместно с его правовым свойством. Например, п. 2 ст. 3 Федерального закона от 26 декабря 2008 г. № 294-Ф3 «О защите прав юридических лиц и индивидуальных предпринимателей при осуществлении государственного контроля (надзора) и муниципального контроля» закрепляет «презумпцию добросовестности юридических лиц, индивидуальных предпринимателей». Также, ст. 315 Кодекса торгового мореплавания РФ, имеет соответствующее название «Презумпция невиновности судов», которая поясняет, что ни одно из участвовавших в столкновении судов не предполагается виновным, если не доказано иное.

Важно отметить, что термин «презумпция» не употребляется непосредственно в правовой норме статьи, а имеет место лишь в названии статьи (например, ст. 1.5 КоАП РФ, ст. 14 УПК РФ).

Что касается косвенных презумпций, то к ним относятся «подразумевающиеся» положения, не имеющие непосредственного правового закрепления в качестве презумпции, но вытекающие из смысла правовой нормы посредством осуществления толкования нормы права или умозаключения.

Важно отметить, что косвенные презумпции преимущественно создаются Конституционным Судом РФ, что придает им особый статус.

Однако и в этой классификации имеют место спорные аспекты, мнения по данному вопросу у исследователей разделились. Далеко не все авторы поддерживают идею о выделении косвенных презумпций, обосновывая это сложностью их нахождения в тексте закона, что, возможно, обусловило соответствующие проблемы в случае непризнания косвенных презумпций как таковых. Но в противовес выделения такой разновидности как косвенные презумпции ученые указывают, что появление такого вида презумпций может повлечь потерю определенной формы презумпции, отсюда возможно злоупотребление выделением значительного количества новых презумпций при их признании и может способствовать тому, что при увеличении количества презумпций, потеряется сам смысл и назначение презумпций.

Нельзя не отметить, что зачастую в правовой норме содержится не само предположение о чем-либо, а определенное правило, вытекающее из законодательно закрепленной нормы права (в пример можно привести презумпцию знания закона). Видимо такой важный, сущностный аспект, многие исследователи не учитывали при дискутировании по вопросам разумности выделения косвенной презумпции.

Отрицание обозначенного классификационного критерия не обосновано, косвенные презумпции действительно имеют место как альтернатива существования презумпции при отсутствии прямого указания на нее в законе, а институт толкования норм права позволяет определить существование правовой презумпции там, 
где законом нет четкого указания на нее, но из специфики общественных отношений ее существование имеет место.

Еще один аргумент того, что нет смысла отрицать существование косвенных презумпций состоит в том, что В их формулировании участвует Конституционный Суд PФ.

3. По отраслевому критерию правовые презумпции можно разделить на материально-правовые и процессуально-правовые.

Если говорить о материально-правовых презумпциях, то они направлены на то, чтобы «закрыть» значимый законодательный пробел, с целью защиты прав и интересов участников правоотношений $[6$, с. 75]. В качестве примера, можно привести презумпции, устанавливающие факты, которые необходимо доказать; презумпции, определяющие предмет доказывания и др.

Процессуальные правовые презумпции, выполняют иные специальные функции, которые необходимы для обеспечительного, технического процесса. Процессуальные правовые презумпции можно подразделить на две группы, где первая группа процессуальных правовых презумпций в административном процессе может быть сопоставлена и отожествлена с другими правовыми презумпциями, содержащимися в иных процессуальных кодексах, таких как ГПК РФ, АПК РФ, к примеру, презумпция надлежащего характера ответчика (ст. 43 КАС РФ), а вторая группа, характеризует специальные процессуальные правовые презумпции, например, презумпция незаконности оспариваемых нормативных правовых актов - ч. 2 ст. 62, ч. 9 ст. 213 КAС РФ.

3. По возможности опровержения правовые презумпции делятся на опровержимые и неопровержимые.

Следует отметить, что в некоторых случаях правоприменитель оставляет за контролирующим лицом право опровергнуть презумпции, что позволило некоторым авторам выделить несколько видов презумпций: опровержимые и неопровержимые.

Где опровержимые презумпции обозначаются с учетом возможности их оспоримости (то есть аргументированного доказательства того, что тот или иной факт не имеет место быть). К таковым можно отнести, например, презумпцию законности административного акта; презумпцию открытости информации в деятельности ОИВ и их должностных лиц; презумпция возмещения морального вреда неправомерными действиями ОИВ и их должностными лицами и др.
Неопровержимые презумпции, которые можно выделить с учетом их безусловности, то есть презумпции, где в норме права не содержится смыслового возможного опровержения. Однако некоторые исследователи высказываю мнения о том, что не рационально обозначать такую разновидность как неопровержимая презумпция, среди таковых можно назвать Е.Б. Тарбагаева, И.В.Решетникова, Я.Л. Штутин, В.П. Воложанин и др. Перечисленные ученые склоняются к выводу о том, что всем презумпциям присуща определенная доля вероятности, поэтому неопровержимых презумпций быть не может.

Весьма категорично по этому вопросу высказывался у В.А. Ойгензихт, который утверждал, что презумпции всегда опровержимы [7, с. 33]. Аналогичного мнения придерживается и М.Л. Давыдова которая подчеркивала в своих работах, что основным свойством презумпции, является ее опровержимость [8, с. 37].

Однако с обозначенными позициями однозначно согласиться не можем, поскольку имеют место и неопровержимые презумпции, с точки зрения смыслового содержания правовой нормы, к примеру, в ст. 1.5 КоАП РФ говориться, что лицо, в отношении которого ведется производство по делу, считается невиновным, пока его вина не будет доказана в соответствующем порядке. Как представляется, в самой норме не предусмотрено никакое опровержение, оно имеет место уже при применении этой нормы, в самом производстве. Конечно, в данном случае презумпция предполагает вероятностное значение, но не в норме права, в которой раскрывается ее смысл.

Также, если говорить о презумпциях-принципах, установленных в конституции РФ, то здесь вполне возможно говорить о неопровержимости презумпции, как принципа Основного закона, к примеру, если говорить о презумпции конституционности нормативного правового акта.

В результате проведенных рассуждений отметим, что помимо того, что большинство существующих презумпций относятся к опровержимым, имеются и исключения, на наш взгляд, презумпция знания закона и презумпция невиновности не относятся к опровержимым презумпциям, поскольку само изложение правовой нормы не несет в себе опровержимого обстоятельства, к примеру, как представляется, из положения ст. 1.5 КоАП РФ о том, что «лицо подлежит административной ответственности только за те административные правонарушения, в отношении которых установлена его вина» не вытекает возможность опровержения нормативной установки, так как опровергается собственно не нормативное установление, а возможность его правоприменения к какому-либо конкретному случаю. 
5. Также в научной литературе интересной представляется следующая классификация правовых презумпций по степени вероятности, которая подразделяет их на: - правовые презумпции с высокой вероятностью,квазипрезумпции; - презумпции с неустойчивой вариантностью, которые выражаются в различного рода частноутвердительных суждениях о факте (в своем большинстве, такая разновидность наиболее свойственна для гражданско-правовых отношений, но исключать межотраслевую связь этого вида мы не станем, поскольку считаем возможным выделить презумпцию возмещения морального вреда, причиненного неправомерными действиями органов исполнительной власти и их должностными лицами).

Данная классификация, представляется весьма узкой, которая переформулирует подразделение правовых презумпций на опровержимые и неопровержимые, с определенной долей конкретизации, что, по большому счету, не меняет сущностного положения рассматриваемой категории.

6. Интересной и рациональной для исследования классификацией правовых презумпций видится их характеристика по такому критерию, как обязательности для суда, к таковым можно отнести следующие виды: императивные презумпции (с определенным в законе фактом-основанием, в том числе конкретизируемым усмотрением суда с учетом обязательности для суда) например, презумпция соответствия цены оказанной государственной услуге; - диспозитивные презумпции (с определенным в законе фактом-основанием, в том числе конкретизируемым усмотрением суда), например, в случае, когда судьей назначается экспертиза, а участники производства по делу всячески препятствуют ее проведению или сами отказываются принимать в ней участие (когда это необходимо), то в этом случае правоприменяющее лицо уполномочено признать тот факт, который должен быть определен в ходе экспертизы. Обозначенные разновидности, на наш взгляд, позволяют более детально рассмотреть институт правовых презумпций с учетом их обязательности для уполномоченного должностного лица.

Таким образом, из всей совокупности существующих в юридической литературе классификаций правовых презумпций, относительно реализации правового регулирования посредством государственного администрирования, можно обозначить следующую систему классификационных критериев, способных качественно охарактеризовать виды правовых презумпций.

1. Общеправовые (общеотраслевые) презумпции, которые подразделяются по сфере действия: а) с учетом направленности на реализацию государственных функций посредством принятия правомерных решений; б) с учетом рассмотрения через призму содержания их в правовой норме и нормативно-правовом акте; в) с учетом юридических предположений, обусловленных характеристикой правоприменительной деятельности непосредственно государственных органов; г) с учетом юридических предположений, направленных на характеристику отдельных видов правоприменительной деятельности; д) с учетом способности охарактеризовать определенное правовое поведение субъектов правоотношения (например, презумпция невиновности).

2. Отраслевые презумпции, которые подразделяются с учетом производной от конституционной презумтивности и деления на отрасли права и межотраслевые презумпции, которые подразделяются с учетом предположения о существовании универсальных однотипных фактов, закрепленных в правовых нормах различных отраслей права, влекущих одинаковые юридические последствия.

3. Специально правовые (отраслевые) презумпции, которые можно выделить с учетом особенностей реализации государственного администрирования (например, презумпция добросовестности уполномоченного должностного лица, при оказании государственной услуги населению).

4. Прямые презумпции, которые можно выделить в соответствии с непосредственным закреплением в нормативно-правовом акте (например, презумпция невиновности) и косвенные презумпции, которые можно выделить с учетом «подразумевающихся» положений, не имеющих непосредственного правового закрепления в качестве презумпции, но вытекающих из смысла правовой нормы посредством осуществления толкования нормы права или умозаключения (например, скрытые правовые презумпции, презумпции, создаваемые Конституционным Судом РФ).

5. Материально-правовые презумпции, которые можно выделить с учетом возможности восполнения пробелов (например презумпции, устанавливающие устанавливаются факты, которые необходимо доказать) и процессуально-правовые презумпции с учетом выполнения специальных индивидуальных функции, необходимых для отправления правосудия (например, группа процессуальных правовых презумпций в административном процессе и группа процессуальных правовых презумпций).

6. Опровержимые презумпции, которые можно выделить с учетом возможности оспоримости (например, презумпция добросовестности) и не опровержимые презумпции, которые можно выделить с учетом их безусловности, то есть презумпции, 
которые в норме права не содержит смыслового возможного опровержения (например, презумпция знания закона (ст. 67.4 Конституции РФ).

7. Императивные презумпции (с определенным в законе фактом-основанием, в том числе конкрети- зируемым усмотрением суда с учетом обязательности для суда) и диспозитивные презумпции (с определенным в законе фактом-основанием, в том числе конкретизируемым усмотрением суда).

\section{ЛИТЕРАТУРА}

1. Барабаш А. С. Понятие «презумпция»: основания появления и использование в правовой деятельности // Российский юридический журнал. 2019. № 4. C. $42-55$.

2. Зацепина 0. Е. Классификация правовых презумпций // Актуальные проблемы российского права. 2018. № 2. С. 80-87.

3. Бабаев В. К. Презумпции в советском праве. Горький, 1974. С. 113-118.

4. Зражевская Т. Д. Презумпции в конституционном праве России // Юридическая техника. Ежегодник. Первые Бабаевские чтения: «Правовые презумпции, теория, практика, техника». Нижний Новгород, 2010, № 4. С. 35-40.

5. Сандугей А.Н. К вопросу о сущности государственного администрирования в сфере миграции // Административное право и процесс. 2016. № 12. С. 29-33.

6. Булаевский Б. А. Классификация правовых презумпций // Журнал российского права. 2010. № 11. С. 75.

7. Ойгензихт В. А. Понятие гражданско-правовой презумпции // Советское государство и право. 1975. № 10. С. 33.

8. Давыдова М. Л. Теоретические и методологические проблемы понятия и состава юридической техники: автореф. дис. .. д-ра юрид. наук. Волгоград, 2010. C. 37.

( Дудко Дмитрий Анатольевич ( Dmitriy.Dudko@lukoil.com ).

Журнал «Современная наука: актуальные проблемы теории и практики»

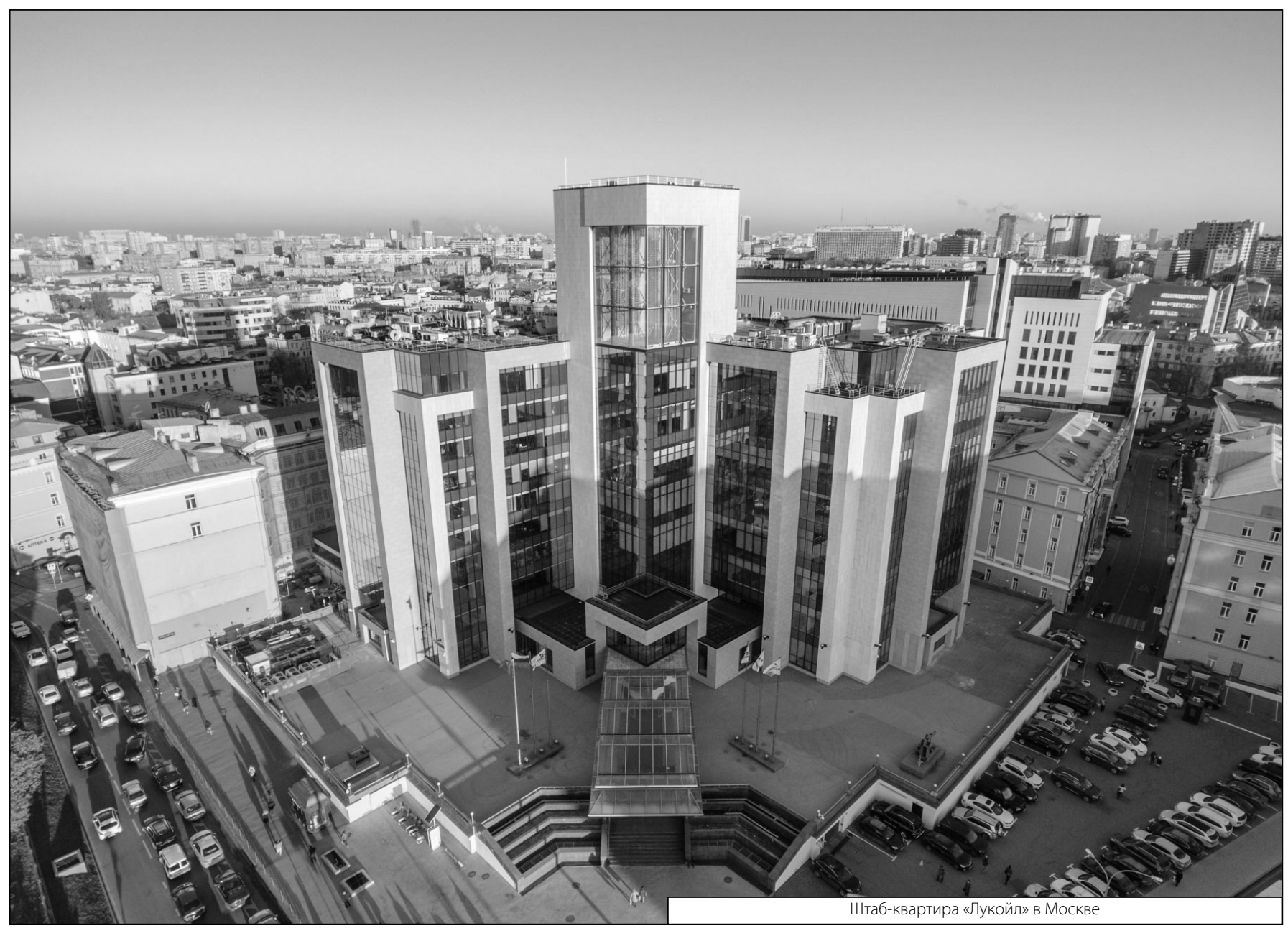

